\title{
Transformational Leadership, Organizational Culture and Sustainability at the Property Development Companies in Malaysia
}

\author{
Salasiah Abbas, Norhani Bakri
}

\begin{abstract}
Sustainability is considered a significant element for property development industry. According to the United Nations General Assembly Brundtland Report, protecting the environment and the society in the midst of human seeking economic growth is at times taken for granted. The motivation behind this study is to seek deeper understanding of the role of transformational leadership in promoting sustainability in Malaysian property industry. The study aims to determine the relationship between transformational leadership and sustainability among the top management level at the property development companies in Malaysia, through the mediating effect of organisational culture that would lead to sustainability in terms of environmental, economy and society. The study employed a purposive sampling method with data collected from managerial level staffs from 100 property development companies in Malaysia. Multivariate data normality tests, descriptive statistics, and structural equation modelling through Smart PLS was used for data analysis. The findings of this study revealed a positive and significant relationship between transformational leadership and sustainability and also a significant positive relationship between transformational leadership and organisational culture namely bureaucratic culture, innovative culture and supportive culture. However, the results established insignificant relationship between organisational culture and sustainability and confirmed that organisational culture does not mediate the relationship between transformational leadership and sustainability. The results confirm that the real estate development company practicing leadership transformation at management level will promote sustainability. This study has contributed to the literature by introducing new empirical evidence not only in organisational studies on the role of transformational leadership practices in promoting sustainability, but also empirical evidence on the insignificant relationship between organisational culture and sustainability as well as the mediating role of organisational culture that is not evident between transformational leadership and sustainability in property development companies Malaysia. Therefore, this study recommended organisations to invest on transformational leadership trainings to support the leadership behaviours that encourages organisational culture that in turn supports sustainability.
\end{abstract}

Keywords: organizational culture, sustainability, transformational leadership, property development companies

Revised Manuscript Received on October15, 2019

* Correspondence Author

Salasiah Abbas*, Azman Hashim International

Business School, Universiti Teknologi Malaysia, Johor Bahru, Johor

Malaysia,E mail : salasiah2005@yahoo.com

Norhani Bakri, School of Human Resource Development and Psychology, Faculty of Social Sciences \& Humanities, Universiti Teknologi Malaysia, E mail :m-nhani@utm.my

\section{INTRODUCTION}

$\mathrm{T}$ societies and across nations, whether industrialized or developing. Sustainability is by nature an interdependent and multifaceted phenomenon that integrates the traditional and predominant economic bottom line with social and environmental imperatives [1]. It refers to the ability to ensure the balance of conserving the natural resources, protecting the environment and social fairness while chasing economic growth. In order to achieve sustainability, the three elements of protection of the environment, economic efficiency and social fairness must be combined. Elkington argued that in order to achieve long-term successful results of sustainable development, all total concept of sustainability considering the perspectives environmental, social as well as economic, needs to be implemented in organisations core business [2].

In particular, property development poses one of the highest impact on sustainability. Previous researchers [3-5] have opined that the biggest contributor to the global environmental degradation is the real estate sector. Specifically in Malaysia, the challenges in adopting green technologies in its construction industry include short of competency and capacity in green technology, overlapping roles of government agencies, slow government programmes, lack of research and innovation and lack of awareness on green implementation cost and benefits [5]. Shen et al. (2006) also found the same challenges on achieving sustainability including concerns on financial, contract time limitation, environmental management methods, passive environmental conservation culture in the construction industry and lack of cooperation among project players. Nevertheless, despite the initiatives taken by the Malaysian government to address sustainability issues in its policies and plans, the country is still behind in terms of implementation and assessment of the implementation [6]. This weakness has been regarded as the absence of comprehensive approaches or frameworks and lack of sufficient sustainable development indicators.

With all the struggles towards sustainability worldwide since 1970s described above, leadership is believed to be one of the key success factors to achieve the targets [1]. Previous literatures have indicated that one of the attributes of sustainability today is the role of leadership [7-11]. 


\section{Transformational Leadership, Organizational Culture and Sustainability at the Property Development Companies in Malaysia}

Researchers believed that while organisations manoeuvre their sustainability strategies, they need to have leadership to guide organisations towards achieving sustainability especially at times of uncertainty and dynamic environment. At the same time, researchers also found that, not only leadership can instil control, leadership will also enable collective intelligence and informal dynamics in human systems [12]. Dess and Picken suggest that the demands of the changing environment present a complex set of challenges [13]. It requires a shift in focus where leaders need to meet the challenges by stimulating innovation, creativity, and responsiveness, and learning to manage change without losing strategic focus or spinning out of control. Muralidharan and Pathak also highlighted the importance of the role of leadership in developing and implementing agendas for sustainability that in turn maximizes the goals of sustainable development of society [11]. They argued that transformational leaders that instill sustainability practices into the fabric of society and also quoted Avolio et al that the transformational leaders 'raise followers' aspirations and activate higher order motives (of sustainability), such that followers identify with the leader and his or her mission or vision [14]. Meanwhile, Robertson and Barling also argued that leaders can encourage their subordinates to engage in workplace pro-environmental behaviors by focusing the four transformational leadership behaviors [15].

Organisational culture is promoted by Bass transformational leadership's Four I's which consist of idealized influence, inspirational motivation, intellectual stimulation and individualized consideration [16]. Leaders promote long term commitments where they share mutual interests and interdependence with their followers [17]. Other researchers like Carrillat, Jaramillo and Locander also argued that transformational actions respond to culture and structure in the overall leadership process [18]. They also argued that transformational leadership drives organisational change that leads to organisational culture. Transforming characteristics include focus of attention, goal directed activity with systematic monitoring and assessment of progress, modelling of positive behaviour and human development and empowerment [19]. In other words, employees will follow leaders towards achieving organisational goals if the leader is seen as trustworthy. Employees, having shared values and norms, create an organisational culture essential to achieve common goals [20].

Ofori and Toor found that leadership is essential to drive the construction industry towards sustainability where transformational leaders provide vision, strategy and direction towards society's common goal of a sustainable future by embedding sustainability strategies in their organisational culture [21]. Other previous studies also link transformational leadership and organisational culture [17, $22,23]$. Both transformational leadership and organisational culture play important roles on the success of an organisation [17]. For example, transformational leaders influence organisational culture by helping organisations see the world in different ways [23]. As the external environment of the organisation changes, transformational leaders influence organisational culture by helping organisations adapt to this new environment [24]. Furthermore, Opoku and Fortune (2011) maintained that leadership plays a vital role towards achieving sustainability through an organisational culture that understands and supports the endeavour. This

is similar to the opinion of Taylor (2009) that believe that to change an organisation towards the organisational culture that supports sustainability, we must change the leaders' behaviour and attitude towards sustainability.

\section{MATERIAL AND METHODS}

For the purpose of this study, Wallach's [42] framework is adapted as illustrated at Figure 1. This model demonstrates an important mechanism through transformational leadership enhances employee motivation by shaping the appropriate organisational culture and in turn, achieves sustainability. In the same context, this study suggests that organisational culture is an important mediator that could play an effect between transformational leadership and sustainability. Specifically, based on earlier arguments, transformational leadership is expected to have significant impact on organisational culture.

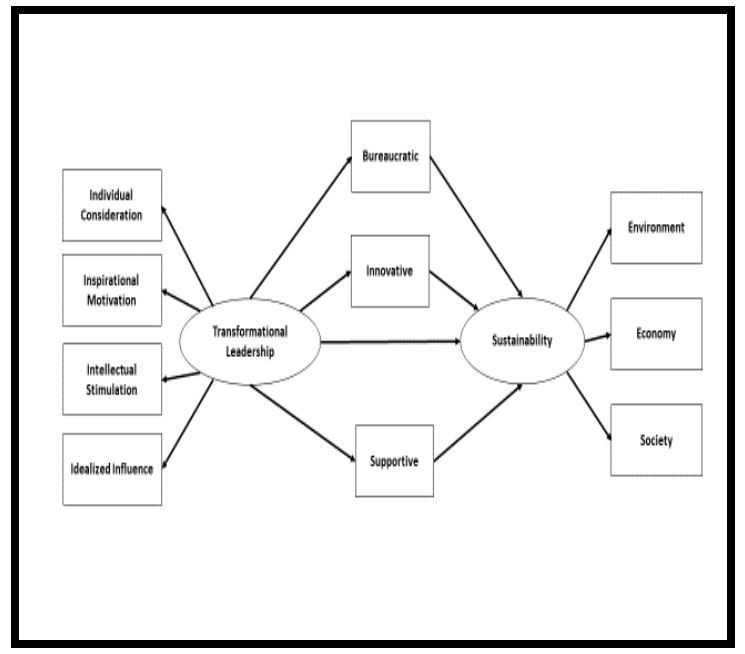

Figure 1: Conceptual Model

The previous studies described Malaysian companies as adopting a mixture of bureaucratic culture, innovative culture and supportive cultures [25]. Here, organisational culture refers to the shared values embraced in property development companies in Malaysia and the norms essential to achieve common goals of, in the context of this study, sustainability. Wallach's (1983) cultures for this study refers to:

i. Bureaucratic culture - company culture that is hierarchical and compartmentalized, with setting clear lines of responsibility and authority

ii. Innovative culture - company culture that is creative, results-oriented and challenging work environment

iii. Supportive culture - where teamwork and a people-oriented, encouraging and trusting work environment is displayed

This study argues that organisational culture is an important factor to help leaders achieve sustainability. The researcher suggest that transformational leadership do have significant impact on sustainability but the mind-set and values of all other individuals and stakeholders of the organisation must also be align with what the leaders and organisation want to achieve.

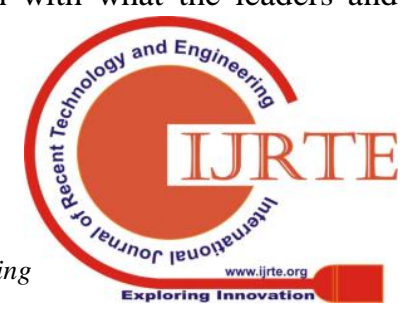


Meanwhile, in the context of built industry in Malaysia, promoting sustainability and facing its challengers, leaders must have adaptability and create organisation systems and initiatives that go beyond their traditional boundaries. Leaders need to go beyond ordinary acts and operate with passion and purpose of all of the individuals involved. Property development companies in Malaysia need leadership that provide the vision, strategy and direction towards a sustainable future. This include inspiring, stimulating, motivating and influencing the employees to have common values of sustainability as part of the organisational culture, thus together achieve sustainability goals.

Subsequently, questionnaires were used to obtain information from the management staffs at the property development in Malaysia as respondents. It was developed from the "Transformational Leadership" Short-form Multifactor Leadership Questionnaire (MLQ-5X) by Bass and Avolio (1995), the "Organisational Culture Index" questionnaire by Wallach (1983) and the "TBL of Sustainability" questionnaire by Elkington (1997). Data was collected through e mails and phone calls to 100 companies by using the purposive sampling method, to identify the top management staffs to answer the questionnaires. The selection of respondents were based on their position which reflects on their in providing leadership and decision making, the operational definition of a management staff who is involve in managing subordinates making decisions and also the knowledge and understanding of the respondents on leadership, sustainability and organisational culture of their company. The data is then analysed by using the Structural Equation Modelling (SEM) SMARTPLS software.

\section{FINDINGS}

Figure 2 shows that sustainability based measures is able to explain $49.7 \%$ of the variance in environment based measures, $49.4 \%$ of the variance in economy based measures and $47.8 \%$ of the variance in social based measures. The values are acceptable as they meet the criteria as stated by Cohen (1988) that claimed R2 values for endogenous latent variables are assessed as substantial for value of 0.26 , moderate for value of 0.13 and weak for value of 0.02 . On the other hand, $18.2 \%$ of the variance in sustainability based measures is explained by organisational culture namely bureaucratic culture, innovative culture and supportive culture. This research focused on R2 of organisational culture and transformational leadership that has been grouped to four main constructs or transformational leadership 4I's namely, idealised influence, intellectual stimulation, individualised consideration and inspirational motivation. Transformational leadership is able to explain $23.5 \%$ of the variance in bureaucratic culture, $22.8 \%$ of variance in innovative culture and $11.8 \%$ of variance in supportive culture. Finally, transformational leadership based measures is able to explain $89.5 \%$ of the variance in idealised influence based measures, $99.4 \%$ of the variance in intellectual stimulation based measures, $47.6 \%$ of the variance in individualised consideration based measures and $47.2 \%$ of the variance in inspirational motivation based measures.

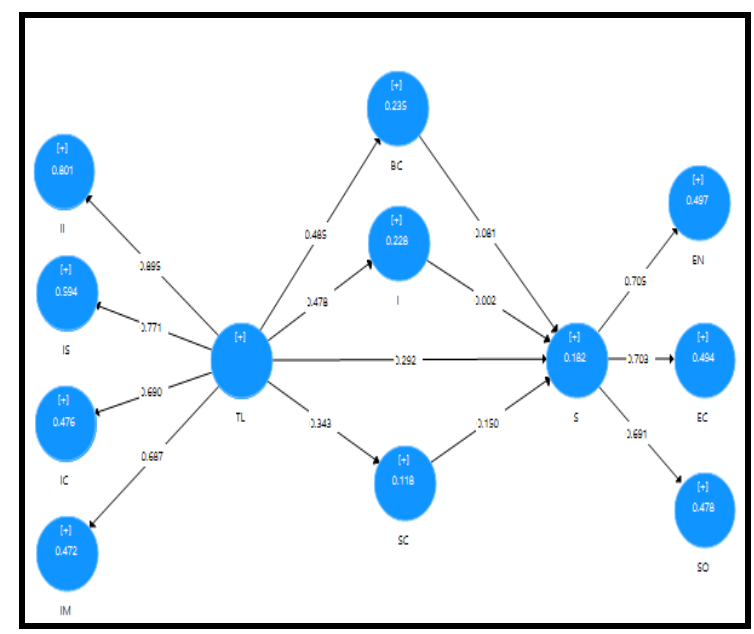

Figure 2 : Results of Structural Model

The relationships between independent and dependent variables were examined by using the SmartPLS 3.0 algorithm output. However, the significant level and $\mathrm{t}$-statistics for all paths were generated using the SmartPLS bootstrapping function where t-statistics output and the significant level of each relationship is determined.

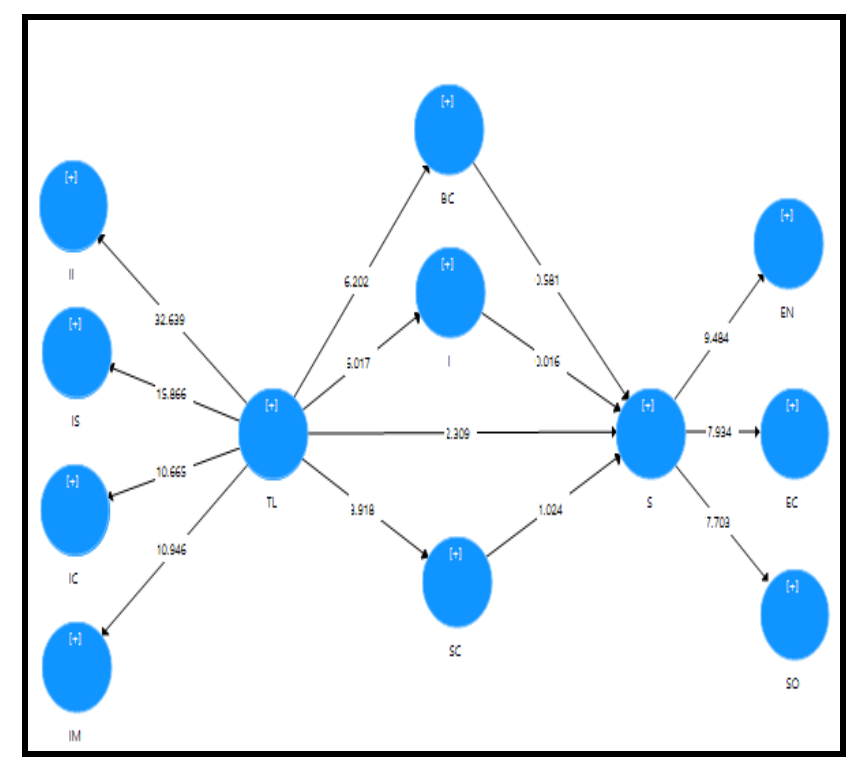

Figure 3 : Results of Direct Relationships

Based on the analysis, it shows that sustainability is directly influenced by transformational leadership $(\beta=0.292, t=2.309$, $\mathrm{p}<0.01)$. Similarly, bureaucratic culture, innovative culture and supportive culture are also directly influenced by transformational leadership with the respective value $(\beta=0.485, \mathrm{t}=6.202, \mathrm{p}<0.01),(\beta=0.478, \mathrm{t}=6.017, \mathrm{p}<0.01)$ and $(\beta=0.343, t=3.918, p<0.01)$. On the other hand, sustainability is not influenced directly by bureaucratic culture $(\beta=-0.081$, $\mathrm{t}=0.561, \mathrm{p}=$ not significant $)$, innovative culture $(\beta=0.002$, $\mathrm{t}=0.016, \mathrm{p}=$ not significant $)$ and supportive culture $(\beta=0.150$, $\mathrm{t}=1.024, \mathrm{p}=\mathrm{not}$ significant). Meanwhile, sustainability is directly influenced by inspirational motivation $(\beta=0.262$, $\mathrm{t}=2.496, \mathrm{p}<0.01$ ). 


\section{Transformational Leadership, Organizational Culture and Sustainability at the Property Development Companies in Malaysia}

However, sustainability is not influenced directly by idealised influence $(\beta=0.143, \mathrm{t}=1.086, \mathrm{p}=$ not significant $)$, intellectual stimulation $(\beta=0.076, \mathrm{t}=0.650, \mathrm{p}=$ not significant $)$, individualised consideration $(\beta=0.077, \quad \mathrm{t}=0.493, \quad \mathrm{p}=$ not significant).

Bureaucratic culture is directly influenced by idealised influence $(\beta=0.297, \mathrm{t}=2.356, \mathrm{p}<0.01)$. On the other hand, bureaucratic culture is not influenced directly by intellectual stimulation $\quad(\beta=0.128, \quad \mathrm{t}=1.114, \quad \mathrm{p}=$ not significant $)$, individualised consideration $(\beta=0.043, \mathrm{t}=0.361, \quad \mathrm{p}=\mathrm{not}$ significant) and inspirational motivation $(\beta=0.148, \mathrm{t}=1.179$, $\mathrm{p}=$ not significant). Meanwhile, innovative culture is directly influenced by intellectual stimulation $(\beta=0.253, \mathrm{t}=2.649$, $\mathrm{p}<0.01$. However, innovative culture is not influenced directly by idealised influence $(\beta=0.173, \mathrm{t}=1.444, \mathrm{p}=$ not significant), individualised consideration $(\beta=-0.020, \mathrm{t}=0.187$, $\mathrm{p}=$ not significant $)$ and inspirational motivation $(\beta=0.218$, $\mathrm{t}=1.830, \mathrm{p}=$ not significant). However, the results show that supportive culture is not influenced directly by idealised influence $\quad(\beta=0.137, \quad \mathrm{t}=0.967, \quad \mathrm{p}=$ not $\quad$ significant $)$, individualised consideration $(\beta=-0.128, \mathrm{t}=0.762, \quad \mathrm{p}=$ not

significant) and inspirational motivation $(\beta=0.067, \mathrm{t}=0.486$, $\mathrm{p}=$ not significant).

The mediation analysis found that bureaucratic culture does not mediate the relationship between transformational leadership and sustainability. The indirect effect determined is $0.039(0.485 * 0.081)$ and is not significant with $\mathrm{t}$-value of $0.558, \mathrm{p}<0.05$ at $95 \%$ CI [-0.101-0.172. Similarly, innovative culture does not mediate the relationship between transformational leadership and sustainability where the indirect effect determined is $0.001(0.478 * 0.002)$ and is not significant with $\mathrm{t}$-value of $0.016, \mathrm{p}<0.05$ at $95 \% \mathrm{CI}$ [-0.136-0.141]. Finally, supportive culture also does not mediate the relationship between transformational leadership and sustainability, the indirect effect determined is 0.051 $(0.343 * 0.150)$ and is not significant with $\mathrm{t}$-value of 0.946 , $\mathrm{p}<0.05$ at $95 \%$ CI [-0.046-0.167]. Table I shows the summary of indirect effect, confidence interval and t-values. Overall, organisational culture i.e. bureaucratic culture, innovative culture and supportive culture; is found to have insignificant mediation effects on the relationship between transformational leadership and sustainability

Table I : Summary of Indirect Effect, Confidence Interval and T-values (Indirect Relationship)

\begin{tabular}{|c|c|r|r|r|r|r|r|r|r|}
\hline & & & & & & \multicolumn{2}{|c|}{$\begin{array}{c}\text { Bootstrapped } \\
\text { Confidence } \\
\text { Interval }\end{array}$} & \\
\hline Hyp & Relationship & Path a & Path b & $\begin{array}{c}\text { Indirect } \\
\text { Effect }\end{array}$ & P-value & T-value & 95\% LL & $\begin{array}{c}\text { 95\% } \\
\text { UL }\end{array}$ & Result \\
\hline H8 & TL -> BC -> S & 0.499 & -0.021 & -0.010 & 0.899 & 0.127 & -0.168 & 0.154 & No Mediation \\
\hline H9 & TL -> I -> S & 0.473 & 0.111 & 0.052 & 0.562 & 0.580 & -0.132 & 0.234 & No Mediation \\
\hline H10 & TL -> SC -> S & 0.425 & 0.113 & 0.048 & 0.559 & 0.585 & -0.099 & 0.216 & No Mediation \\
\hline
\end{tabular}

Note: $\mathrm{TL}=$ Transformational Leadership; $\mathrm{BC}=$ Bureaucratic Culture; $\mathrm{I}=$ Innovative Culture; $\mathrm{SC}=$ Supportive Culture; $\mathrm{S}=$ Sustainability

\section{DISCUSSION}

The findings conclude that there is a significant relationship between transformational leadership and sustainability and also significant relationship between transformational leadership and organisational culture namely bureaucratic culture, innovative culture and supportive culture in the property development companies in Malaysia. However, there is no significant relationship between bureaucratic culture, innovative culture and supportive culture and sustainability in the property development companies in Malaysia. The results of analysis demonstrated that bureaucratic culture, innovative culture and supportive culture do not mediate the relationship between transformational leadership and sustainability. In other words, the relationship between transformational leadership and sustainability is not mediated by organisational culture. This finding is in contrast with previous that found the mediating effect of organisational culture (Wipulanusat, Panuwatwanich and Stewart, 2018; Pradhan, Panda and Jena, 2017; Al-Ali, Singh, Al-Nahyan and Sohal, 2017; Sattayaraksa and Boon-itt, 2016; Hussain, Wan Ismail, Rashid and Nisar, 2016; Shim, Jo and Hoover, 2015; Cegarra-Leiva, Sánchez-Vidal and Cegarra-Navarro, 2012 and Panuwatwanich, Stewart and Mohamed, 2008).

Transformational leader's direct behaviour on employees, such as motivation, relationship orientation could influence their emotional interests and enable direct and clear hints that leaders expect them to pursue sustainability. In other words, transformational leadership itself is an essential element in achieving sustainability as highlighted by Opoku and Fortune (2011) which emphasized that leadership plays a vital role towards achieving sustainability through an organisational culture that understands and appreciate the notion. Similarly, Taylor (2009) also highlighted that to change an organisation towards the organisational culture that supports sustainability, it must come hand and in hand with changing the organisational leaders behaviour and attitude towards a more sustainable organisation. This is because the leaders will lead the culture towards what their vision and goals. Meanwhile, Opoku et al also believed that the key element in achieving sustainability is culture [26]. This is because culture frames people's relationships and attitudes towards the built and the natural environment. This shows that in the context of property development companies in Malaysia, organisational culture is not towards sustainability.

\section{CONCLUSION}

The practices of transformational leadership lay the foundation for organisational culture, which in turn results in promoting sustainability. Leaders in the property development companies have the responsibility to create the organisational culture that supports the sustainability endeavour. 
Organisational culture is needed to achieve sustainability while leadership is needed to embed such organisational culture to influence all stakeholders to achieve the common objectives. The shared values in an organisational culture enhance sustainability awareness which have influence on pro-sustainability behaviour at workplace. Therefore, the property development companies in Malaysia should include transformational leadership programs and training courses in their annual plans, with more attention to intellectual stimulation towards employees. They should take into consideration on investing in transformational leadership trainings to support the leadership behaviours that encourage organisational culture that in turn support sustainability and overcome resistance resulting from changes and challenges. Therefore, these companies should focus on hiring managers that have attributes of transformational leadership in order to promote sustainability.

\section{REFERENCES}

1. Feyerherm, A. E. \& Parker, S. B. (2015). Chapter 5 Emergent Collaboration \& Leadership For Sustainable Effectiveness: The Metropolitan Housing Authority In Organizing For Sustainability. Published Online: 12 Mar 2015; pp 127-153.

2. Elkington, J. Enter The Triple Bottom Line, In Henriques, A. \& Richardson, J. (Eds), The Triple Bottom Line: Does It All Add Up? Earthscan, London, 2004, Pp. 1-16.

3. Kibert, C.J. The Next Generation Of Sustainable Construction, Building \& Information, Vol. 35 No. 6, Pp. 595-601, 2007.

4. Lützkendorf, T., Fan, W. \& Lorenz, D. "Engaging Financial Stakeholders", Opportunities For A Sustainable Built Environment, Building Research \& Information, Vol. 39, N 5, Pp. 483-503. 2011.

5. Sim, Y.L \& Putuhena, F, J, "Green Building Technology Initiatives To Achieve Construction Quality \& Environmental Sustainability In The Construction Industry In Malaysia", Management Of Environmental Quality: An International Journal, Vol. 26 Issue: 2, Pp.233-249,

2015. Https://Doi.Org/10.1108/MEQ-08-2013-0093(URL)

6. Saadatian, Omid \& Lim, Chin Haw \& Sohif, Mat \& Sopian, Kamaruzzaman \& Dalman, Masoud \& Salleh, Elias. (2011), Sustainable Development In Malaysia-Planning \& Initiatives, Solar Energy Research Institute, Universiti Kebangsaan Malaysia, Faculty Of Design $\&$ Architecture, Universiti Putra Malaysia.

7. Muller, R \& Turner, J.R. (2010). Attitudes \& Leadership Competences For Project Success. Baltic Journal Of Management, Vol. 5 Issue: 3, Pp.307-329

8. Muller, R \& Turner, J.R. (2010). Leadership Competency Profiles Of Successful Project Managers. International Journal Of Project Management, Vol. 28, No. 5, Pp. 437-448.

9. Müller, R., \& Jugdev, K. (2012). Critical Success Factors In Projects: Pinto, Slevin, \& Prescott - The Elucidation Of Project Success. International Journal Of Managing Projects In Business, 5(4), Pp. $757-775$.

10. Meng, J, Xue, B, Liu, B \& Fang, N. (2015), Relationships Between Top Managers Leadership \& Infrastructure Sustainability A Chinese Urbanization Perspective, Engineering, Construction \& Architectural Management, Vol. 22 Iss 6 Pp. $692-714$.

11. Muralidharan and Pathak (2018). "Sustainability, Transformational Leadership and Social Entrepreneurship" https://www.researchgate.net , publication 323264606_Sustainability_Transformational Leadership and Social Entrepreneurship...

12. Marion, R., \& Uhl-Bien, M. (2007), Paradigmatic Influence \& Leadership: The Perspectives Of Complexity Theory \& Bureaucracy Theory. In J. K. Hazy, J. Goldstein \& B. Lichtenstein (Eds.), Complex Systems Leadership Theory (Pp. 143-159). New York, NY: ISCE Publishing.

13. Dess, G.G \& Picken, J.C (2000), Changing Roles: Leadership In The 21st Century, Organisational Dynamics, Vol. 28, No. 3, 2000, Pp. 18-34. Doi:10.1016/S0090-2616(00)88447-8

14. Avolio, B.J., Bass, B.M., \& Jung, D.I. "Re-Examining The Components Of Transformational \& Transactional Leadership Using The Multifactor Leadership Questionnaire," Journal Of Occupational \& Organisational Psychology,72 (4), 441-462. 1999.
15. Robertson and Barling (2013). "Greening Organizations Through Leaders “Influence on Employees' Pro-Environmental Behaviours”, , Journal of Organizational Behaviour, Special Issue Article : Greening Organizational Behaviour, Vol.34, Issue 2, Feb. 2013. 176-194.

16. Bass, B. M. (1985). Leadership and Performance Beyond Expectations. New York: Free Press.

17. Ramanaidu, S. K. Uncovering The Relationship Between Transformational Leadership, Organisational Culture, Affective Commitment \& Employee Performance: The Case Of A Malaysian Educational Institution, Faculty Of Business \& Law Newcastle Graduate School Of Business, University Of Newcastle, 2011.

18. Carrillat, F. A., Jaramillo, F., \& Locander, W. B. (2004), Market-Driving Organisations: A Framework, Academy Of Marketing Science Review, (5), Pp: 1-14.

19. Schein, E.H. (1991) Legitimating Clinical Research In The Study Of Organisational Culture (WP\# 3288-91-BPS), Cambridge, MA Masschusetts Institute Of Technology, Sloan School Of Management.

20. Wallach, E. (1983). Individuals \& Organisations: The Culture Match, Training \& Development Journal, 12, 28-36.

21. Ofori, G \& Toor, S.R. "Taking Leadership Research Into Future: A Review Of Empirical Studies \& New Directions For Research", Engineering, Construction \& Architectural Management, Vol. 15 Issue: 4, pp.352-371, 2008. Https://Doi.Org/10.1108/09699980810886856(URL)

22. Tucker, B. A. \& Russell, R. F. "The Influence Of The Transformational Leader", Journal Of Leadership \& Organisational Studies, Vol. 10, No. 4, Pp. 103-111, 2004.

23. Mink, O. (1992), Creating New Organisational Paradigms For Change, International Journal Of Quality \& Reliability Management, 9, Pp: 21-23.

24. Smith, A. "Good Leaders", Business \& Economic Review, 37, pp: 10-12, 1990.

25. Rashid, Z., Sambasivan, M., \& Johan, J. (2003). The Influence Of Corporate Culture \& Organisational Commitment On Performance. Journal Of Management Development, 22 (8), 708-728.

26. Opoku, A., Cruickshank, H. \& Ahmed, V. "Leadership, Culture \& Sustainable Built Environment", Built Environment Project \& Asset Management, Vol. 5 Issue: 2, 2015.

\section{AUTHORS PROFILE}

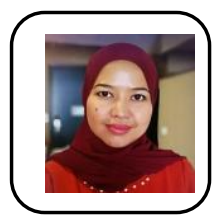

Salasiah Abbas is a PhD student from Azman Hashim International Business School, Universiti Technology Malaysia. Her PhD thesis entitled "The Mediating Effect of Organizational Culture in the Relationship between Transformational Leadership and Sustainability at the Property Development Companies in Malaysia".

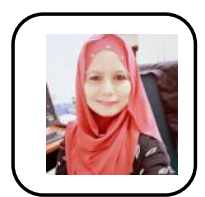

Norhani Bakri is an Associate Professor at School of Human Resource Development and Psychology, Faculty of Social Sciences and Humanities, Universiti Technology Malaysia. A PhD doctorate in Techno Sociology whose research area of specialization includes Industrial Sociology, Employment Relations, Organizational Culture, Transformational Leadership and Workplace Deviance. Awarded with Lifetime Achievement in Humanities and Social Sciences (Sociology) in VIWA 2019 (Chennai) and Best Professor in Human Resources Management by in Asia's Education Excellence Awards 2019 (Singapore). 